\title{
Increasing temperature weakens the positive effect of genetic diversity on population growth
}

\author{
Alexandra L. Singleton ${ }^{1, *}$, Samantha Votzke ${ }^{1}$, Andrea Yammine ${ }^{1}$, Jean P. Gibert ${ }^{1, *}$ \\ ${ }^{1}$ Duke University, Department of Biology, Durham, NC, USA \\ *To whom correspondence should be addressed: alexsingleton2@gmail.com, \\ jean.gibert@duke.edu
}

Key Words: Genetic variability, Intraspecific variation, Intraspecific variability, global warming, microbes

\section{ABSTRACT}

Genetic diversity and temperature increases associated with global climate change, are known to independently influence population growth and extinction risk. Whether increasing temperature may influence the effect of genetic diversity on population growth, however, is not known. We address this issue in the model protist system Tetrahymena thermophila. We test the hypothesis that at temperatures closer to the species thermal optimum (i.e., the temperature at which population growth is maximal), genetic diversity should have a weaker effect on population growth compared to temperatures away from the thermal optimum. To do so, we grew populations of $T$. thermophila with varying levels of genetic diversity at increasingly warmer temperatures and quantified their intrinsic population growth rate, $r$. We found that genetic diversity increases population growth at cooler temperatures, but that as temperature increases, this effect almost completely disappears. We also show that a combination of changes in the amount of expressed genetic diversity $(\mathrm{G})$, plastic changes in population growth across temperatures (E), and strong GxE interactions, underlie this temperature effect. Our results uncover important but largely overlooked temperature effects that have implications for the management of small populations with depauperate genetic stocks in an increasingly warming world. 


\section{INTRODUCTION}

42 Rapid global climate change has a myriad of ecological consequences, from individuals to

43 ecosystems[1-7]. Rising temperatures, in particular, influence metabolic rates[8, 9], which

44 determine reproduction[10-12] and mortality[13, 14], thus setting demographics and population

45 growth $[10,15]$. As a consequence, species have thermal tolerances, and these thermal tolerances

46 ultimately determine where on the globe -and under what environmental conditions- species

47 may survive and reproduce[16, 17]. As temperatures increase globally, whether species will shift

48 their geographic ranges[17], or instead go extinct[2], will be largely determined by these

49 temperature tolerances[18].

51 Genetic diversity has long been known to reduce species extinction risk (e.g., [19]). For example,

52 genetic diversity is negatively related to extinction risk in birds[20], low genetic diversity

53 increases extinction risk in butterflies[21], while genetic rescue (i.e., introduction of new genetic

54 variants) decreases extinction risk in mice[22] and pigmy possums[23]. Genetic diversity thus

55 hedges against changing environmental conditions by increasing the chance that a population

56 will have individuals with high rates of survival in novel environmental conditions. However, a

57 combination of habitat fragmentation and shifting environmental conditions often lead to

58 geographic range reductions (e.g., mountaintop species[2]), or crashes in population size[24].

59 Smaller population size or geographic range strengthens drift and reduces genetic diversity,

60 leading to higher inbreeding depression and extinction risk[19]. While both genetic diversity and

61 temperature are well-known to independently influence population growth(e.g., $[9,19])$, whether

62 increasing temperatures may alter the effect of genetic diversity on population growth and

63 extinction risk is largely unknown. 
65 Here, we address this issue in a model microbial system, the globally distributed protist

66 Tetrahymena thermophila. We do so because the genetic makeup of these organisms can be

67 easily manipulated[25], and because these organisms play an important role in the global carbon

68 cycle that ultimately determines the pace of climate change (i.e., the microbial loop, [26-28]). In

69 particular, we address 1) whether genetic diversity influences population growth in $T$.

70 thermophila, 2) whether temperature influences that effect, and, 3) through what mechanisms.

71 We hypothesize that lower genetic diversity depresses population growth (lower intrinsic growth

72 rate, $r$ ) through inbreeding depression [19], while higher genetic diversity increases growth. We

73 also hypothesize that the effect of genetic diversity should be weaker near the species-level

74 thermal optimum owing to differences in how different genotypes grow across temperatures

75 (Topt, Fig 1a, b): at Topt, most genotypes should reproduce relatively well, while away from

76 Topt, some genotypes may perform increasingly poorly. Consequently, increasing genetic

77 diversity may increase the chance of the population having genotypes that reproduce well at

78 temperatures away from Topt, resulting in a higher intrinsic growth rate with increasing genetic

79 diversity (Fig 1a, b; blue). Conversely, only a weak relationship between genetic diversity and $r$,

80 if any at all, should be observed near or at Topt (Fig 1a, b; red).

82 METHODS

\section{Experimental procedure}

84 We sourced five clonal lines (B2086.2, A*III, CU438.1, A*V, and CU427.4) of the protist

85 Tetrahymena thermophila from the Cornell University Tetrahymena Stock Center. The lines

86 were reared in Carolina Biological protist medium ${ }^{\circledR}$ (Burlington, NC) in $200 \mathrm{~mL}$ autoclaved 
87 borosilicate jars, and a 16-8 day/night cycle at $22^{\circ} \mathrm{C}$ within Percival growth chambers (Perry,

88 IA).

90 To determine whether temperature alters the effects of genetic diversity on population growth,

91 we manipulated the temperature and initial genetic diversity of microcosm populations. To

92 manipulate genetic diversity, we started populations with a varying number of clonal lines $(1,2$,

933,4 or 5 lines). Monoclonal cultures were started with 50 individual protists. For all other

94 treatments, the initial abundance of each clone depended on the total number of clones present,

95 to control for possible effects of initial density: 2-clone populations started with 25

96 individuals/clone, 3-clone populations started with $\sim 16$ individuals/clone, 4-clone populations

97 started with $\sim 12$ individuals/clone, and 5-clone populations started with 10 individuals/clone.

98 Each monoclonal population, and each combination of four and five clones, was replicated 4

99 times. Each combination of two and three clones was replicated twice, for a total of 84

100 experimental populations per temperature. All experimental microcosms were reared in $3 \mathrm{~mL}$ of

101 growth media in $35 \mathrm{~mm}$ petri dishes.

102

103 We crossed the five genetic diversity treatments with four temperature treatments $(19,22,25,28$

$104^{\circ} \mathrm{C}$ ) along the rising portion of the temperature performance curve (TPC) of the species, for a

105 total 336 experimental microcosms. The species TPC was quantified on a well-mixed population

106 (Fig 1c). Experimental microcosms were grown in Percival growth chambers with all other

107 environmental variables mimicking rearing conditions. 
After a 24-hr incubation period, we estimated final population size through whole dish counts

110 under a stereomicroscope (Leica, M205 C). Assuming exponential growth, the intrinsic growth

111 rate $(r)$ of each microcosm population was calculated as $[\log (\mathrm{Nf})-\log (\mathrm{Ni})] /$ time, with time $=1$ day,

$112 N_{f}$ being the final abundance, and $N_{i}$ the initial density (=50 ind for all experimental

113 microcosms).

115 Statistical Analyses

116 To test our hypotheses, we used a linear model with the $\log _{10}$ of $r$ as the response variable and

117 the $\log _{10}$ of the number of clones, temperature, and their interaction, as explanatory variables. To

118 understand the mechanisms behind possible effects of temperature on the relationship between

119 genetic diversity and $r$, we assessed whether changes in total additive genetic variation in $r(\mathrm{G})$,

120 environmental variation in $r(\mathrm{E})$, or GxE interactions, could explain observed changes in $r$ with

121 genetic diversity and temperature. To do so, we used Analysis of Covariance (ANCOVA) on

122 data from the monoclonal populations, with $r$ as the response variable and temperature, clonal

123 line, and their interaction, as explanatory variables.

\section{RESULTS}

126 Population intrinsic growth rate $(r)$ increased with temperature (estimate $=0.03 \pm 0.002, \mathrm{t}=$

127 20.70, $\mathrm{p}<0.001$, Fig $2 \mathrm{a})$ and increased with genetic diversity (estimate $=0.61 \pm 0.09, \mathrm{t}=6.94, \mathrm{p}$

$128<0.001$, Fig $2 \mathrm{a})$. The positive effect of genetic diversity on $r$ decreased with temperature

129 (estimate $=-0.02 \pm 0.004, \mathrm{t}=-5.60, \mathrm{p}<0.001$, Fig $2 \mathrm{a}$ ). ANCOVA results show that this

130 temperature influence on the effects of genetic variation on $r$ is likely due to a combination of 
131 changes in the amount of expressed genetic variation in the populations, G, environmental

132 changes in r, E, and strong GxE interactions (Table 1, Fig 2b).

\section{DISCUSSION}

135 Rapidly changing environmental conditions and genetic diversity are both well-known to

136 independently influence population growth and extinction risk (e.g., [2, 3, 23, 29]). Whether

137 rapid climate change may alter how genetic diversity influences population growth, however, is

138 not known. Our results indicate that as temperature increases toward a species' thermal optimum,

139 genetic diversity has a weaker effect on the intrinsic population growth rate (Fig $2 \mathrm{a})$. These

140 results imply that the effect of genetic diversity on population growth is contingent on

141 environmental conditions.

143 Our results also indicate that changes in expressed additive genetic variation in $r(\mathrm{G})$ are

144 responsible for lower levels of variation observed at higher temperatures, compared to those

145 observed at lower temperatures (Fig 2b, Table 1), while plasticity (E) is responsible for the

146 observed increase in population growth with temperature (Fig 2b). Moreover, strong GxE

147 effects, where different genotypes grow differentially at different temperatures, underlie the

148 weakening of the positive effect of genetic variation on population growth rate (Fig 2a): clonal

149 lines grow at similar rates at warmer temperatures, but do so at distinctly higher or lower rates in

150 colder temperatures (Fig 2b). The presence of strong GxE effectively shifts which genotypes

151 grow better at different temperatures, indicating the possibility for temperature-mediated clonal

152 sorting in these microbial populations. Rapid evolutionary change has been suggested as a

153 possible mechanism through which organisms may fend off the negative impacts of climate 
154 change[30-33]. In line with these studies, our results suggest that rapid evolutionary change (in

155 this case, through clonal sorting), may occur in species where different genotypes display

156 different thermal responses (GxE).

158 Together, our results indicate possible ways in which increasing temperatures associated with

159 climate change and depauperate genetic stocks resulting from habitat fragmentation may jointly

160 affect population growth and extinction risk. We show that temperature and genetic diversity

161 interactively influence population growth: populations with higher genetic diversity have a

162 weaker response to temperature compared to genetically depauperate populations (Fig 2a). As a

163 consequence, while genetic diversity hedges against increasing temperatures, inbred -or small-

164 populations, may respond more strongly. These results have important implications for the

165 management of threatened and other species of interest in a changing world.

\section{ACKNOWLEDGMENTS}

168 We thank Zeyi Han for providing help and expertise with T. thermophila clonal lines and

169 Kathleen Donohue for early discussions. SV, AY and JPG were supported by a U.S. Department

170 of Energy, Office of Science, Office of Biological and Environmental Research, Genomic

171 Science Program Grant under Award Number DE-SC0020362 to JPG. 
(a)

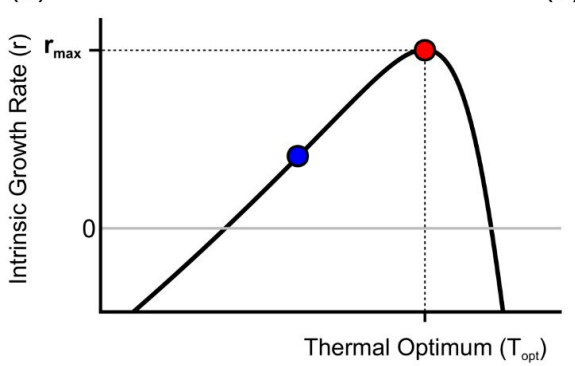

(b)

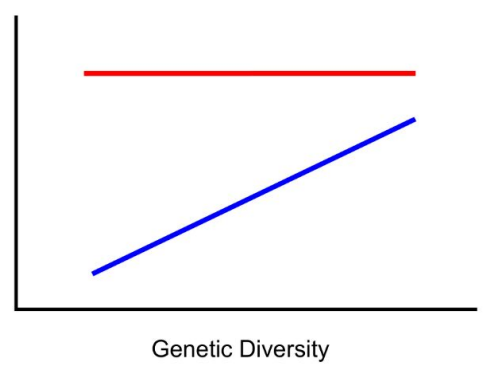

(c)

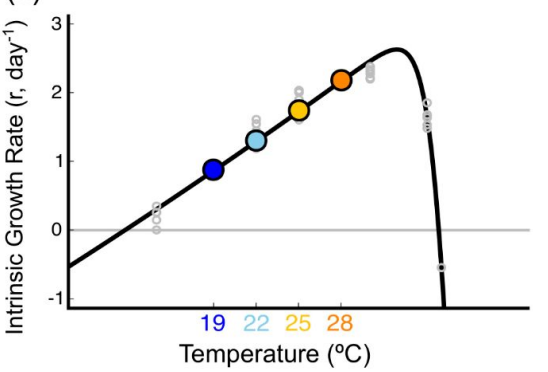

Fig 1: (a) Typical temperature performance curve for the population intrinsic growth rate, $r$, in solid black. Grey solid line represents $\mathrm{r}=0$ : above the line, the population grows, below, it decreases. We hypothesize that at temperatures away (blue dot) from the optimal temperature (Topt, red dot), increasing genetic diversity should lead to increasing intrinsic growth rate (b, blue solid line), while closer to the thermal optimum, increasing genetic diversity should not significantly increase $r$ owing to similar growth rates across genotypes (b, red solid line). (c) Tetrahymena pyriformis temperature performance curve (black line, estimated from real data in grey). Colored dots indicate experimental temperatures $\left(19^{\circ} \mathrm{C}\right.$, deep blue, $22^{\circ} \mathrm{C}$, sky blue, $25^{\circ} \mathrm{C}$, yellow, $28^{\circ} \mathrm{C}$, orange). 
(a)

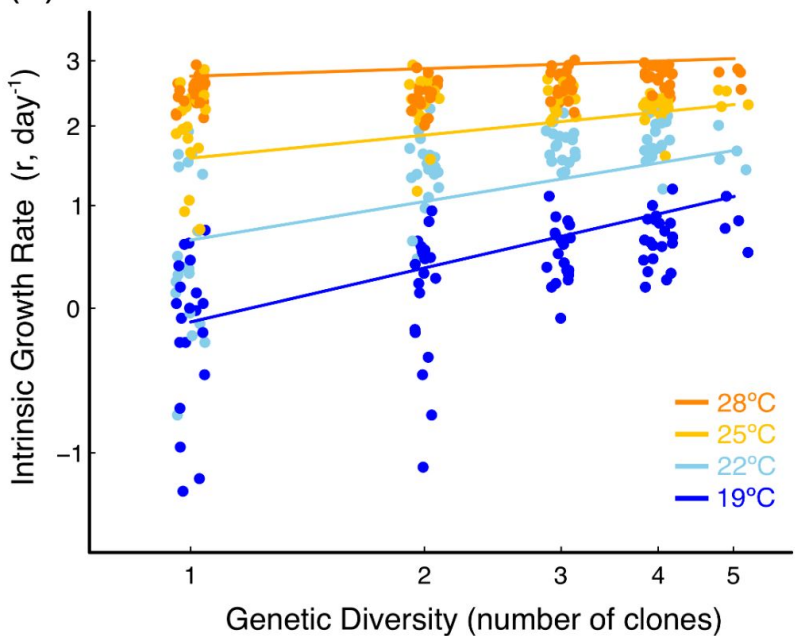

(b)

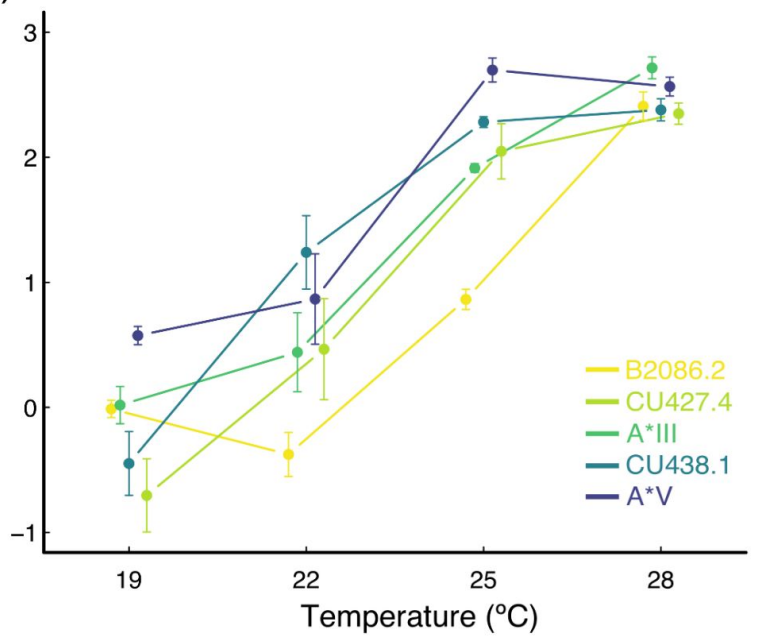

215 Fig 2: (a) Plot of the intrinsic growth rate, $r$, against the number of clones for all 336

216 experimental microcosms (dots), across all four experimental temperatures. Solid lines represent 217 linear model predictions (color code as in Fig 1c). (b) Intrinsic growth rate against temperature 218 for all monoclonal cultures. Bars represent standard errors and lines connecting dots indicate 219 changes in $\mathrm{r}$ across temperatures (B2086.2 is Yellow, CU427.4 is Yellow green, A*III is Green, 220 CU438.1 is Blue green, $\mathrm{A} * \mathrm{~V}$ is Blue). 
243 Table 1: ANCOVA results assessing G, E, and GxE effects in $r$. Boldface indicates significant 244 effects.
Degree of Freedom
F-statistic
p-value

\section{G (differences across} genotypes)

$\begin{array}{llll}\text { At } 19 \mathrm{C}^{\circ} & 3 & 6.56 & \mathbf{0 . 0 0 3} \\ \text { At } 22 \mathrm{C}^{\circ} & 3 & 2.88 & 0.062 \\ \text { At } 25 \mathrm{C}^{\circ} & 3 & 34.6 & <\mathbf{1 0 - 6} \\ \text { At } 28 \mathrm{C}^{\circ} & 3 & 2.88 & 0.059\end{array}$

E (differences across temperatures)

$\begin{array}{rccc}\text { Clone B2086.2 } & 4 & 118 & <\mathbf{1 0 - 8} \\ \text { Clone CU427.4 } & 4 & 26.8 & <\mathbf{1 0 - 5} \\ \text { Clone A*III } & 4 & 48.3 & <\mathbf{1 0 - 7} \\ \text { Clone CU438.1 } & 4 & 42.9 & <\mathbf{1 0 - 6} \\ \text { Clone A*V } & 4 & 32.9 & <\mathbf{1 0 - 6}\end{array}$

GxE (differences across

genotypes across

temperatures)

12

4.70

$<10-5$ 


\section{REFERENCES}

[1] Barnett, T.P., Adam, J.C. \& Lettenmaier, D.P. 2005 Potential impacts of a warming climate on water availability in snow-dominated regions. Nature 438, 303-309. (doi:10.1038/nature04141). [2] Freeman, B.G., Scholer, M.N., Ruiz-Gutierrez, V. \& Fitzpatrick, J.W. 2018 Climate change causes upslope shifts and mountaintop extirpations in a tropical bird community. Proceedings of the National Academy of Sciences 115, 11982-11987. (doi:10.1073/pnas.1804224115).

[3] Pimm, S.L. 2009 Climate disruption and biodiversity. Current biology 19, R595-601. (doi:10.1016/j.cub.2009.05.055).

[4] Bellard, C., Bertelsmeier, C., Leadley, P., Thuiller, W. \& Courchamp, F. 2012 Impacts of climate change on the future of biodiversity. Ecol Lett 15, 365-377. (doi:10.1111/j.1461-0248.2011.01736.x). [5] Gibert, J.P. \& DeLong, J.P. 2014 Temperature alters food web body-size structure. Biology letters 10, 20140473-20140473.

[6] Gibert, J.P., Chelini, M.C., Rosenthal, M.F. \& DeLong, J.P. 2016 Crossing regimes of temperature dependence in animal movement. Global Change Biology 22, 1722-1736. (doi:10.1111/gcb.13245). [7] Gibert, J.P. 2019 Temperature directly and indirectly influences food web structure. Scientific Reports 9, 5312-5312. (doi:10.1038/s41598-019-41783-0).

[8] Gillooly, J.F., Charnov, E.L., West, G.B., Savage, V.M. \& Brown, J.H. 2002 Effects of size and temperature on developmental time. Science 417, 70-73.

[9] Brown, J.H., Gillooly, J.F., Allen, A.P., Savage, V.M. \& West, G.B. 2004 Toward a Metabolic Theory of Ecology. Ecology 85, 1771-1789.

[10] Savage, V.M., Gillooly, J.F., Brown, J.H. \& Charnov, E.L. 2004 Effects of body size and temperature on population growth. The American naturalist 163, 429-441. (doi:10.1086/381872).

[11] Schaper, S.V., Dawson, A., Sharp, P.J., Gienapp, P., Caro, S.P. \& Visser, M.E. 2012 Increasing temperature, not mean temperature, is a cue for avian timing of reproduction. The American Naturalist 179, E55-69. (doi:10.1086/663675).

[12] Zeh, J.A., Bonilla, M.M., Su, E.J., Padua, M.V., Anderson, R.V., Kaur, D., Yang, D.-s. \& Zeh, D.W. 2012 Degrees of disruption: projected temperature increase has catastrophic consequences for reproduction in a tropical ectotherm. Global Change Biology 18, 1833-1842. (doi:10.1111/j.13652486.2012.02640.x). [13] Amarasekare, P. \& Savage, V.M. 2012 A framework for elucidating the temperature dependence of fitness. The American naturalist 179, 178-191. (doi:10.1086/663677).

[14] Amarasekare, P. \& Coutinho, R.M. 2013 The intrinsic growth rate as a predictor of population viability under climate warming. Journal of Animal Ecology 82, 1240-1253. (doi:10.1111/13652656.12112).

[15] Kremer, C.T., Thomas, M.K. \& Litchman, E. 2017 Temperature and size scaling of phytoplankton population growth rates: Reconciling the Eppley curve and the metabolic theory of ecology. Limnology and Oceanography 62, 1658-1670. (doi:10.1002/lno.10523).

[16] Sunday, J.M., Bates, A.E. \& Dulvy, N.K. 2011 Global analysis of thermal tolerance and latitude in ectotherms. Proceedings of the Royal Society B 278, 1823-1830. (doi:10.1098/rspb.2010.1295).

[17] Sunday, J.M., Bates, A.E. \& Dulvy, N.K. 2012 Thermal tolerance and the global redistribution of animals. Nature Climate Change 2, 686-690. (doi:10.1038/nclimate1539).

[18] Calosi, P., Bilton, D.T. \& Spicer, J.I. 2008 Thermal tolerance, acclimatory capacity and vulnerability to global climate change. Biology Letters 4, 99-102. (doi:10.1098/rsbl.2007.0408). [19] Frankham, R. 2005 Genetics and extinction. Biological Conservation 126, 131-140. (doi:10.1016/j.biocon.2005.05.002). [20] Evans, S.R. \& Sheldon, B.C. 2008 Interspecific patterns of genetic diversity in birds: correlations with extinction risk. Conservation Biology 22, 1016-1025. (doi:10.1111/j.1523-1739.2008.00972.x). 
[21] Saccheri, I., Kuussaari, M., Kankare, M., Vikman, P., Fortelius, W. \& Hanski, I. 1998 Inbreeding and extinction in a butterfly metapopulation. Nature 392, 491-494. (doi:Doi 10.1038/33136). [22] Schwartz, M.K. \& Mills, L.S. 2005 Gene flow after inbreeding leads to higher survival in deer mice. Biological Conservation 123, 413-420. (doi:10.1016/j.biocon.2004.11.016). [23] Weeks, A.R., Heinze, D., Perrin, L., Stoklosa, J., Hoffmann, A.A., van Rooyen, A., Kelly, T. \& Mansergh, I. 2017 Genetic rescue increases fitness and aids rapid recovery of an endangered marsupial population. Nature Communications 8, 1071. (doi:10.1038/s41467-017-01182-3). [24] van de Pol, M., Jenouvrier, S., Cornelissen, J.H.C. \& Visser, M.E. 2017 Behavioural, ecological and evolutionary responses to extreme climatic events: challenges and directions. Philosophical Transactions of the Royal Society B 372. (doi:10.1098/rstb.2016.0134). dispersal and life history strategies - Tetrahymena ciliates. BMC Evolutionary Biology 7, 1-15. (doi:10.1186/1471-2148-7-133). [26] Karhu, K., Auffret, M.D., Dungait, J.A.J., Hopkins, D.W., Prosser, J.I., Singh, B.K., Subke, J.A., Wookey, P.A., Agren, G.I., Sebastià, M.T., et al. 2014 Temperature sensitivity of soil respiration rates enhanced by microbial community response. Nature 513, 81-84. (doi:10.1038/nature13604). [27] Gao, Z., Karlsson, I., Geisen, S., Kowalchuk, G. \& Jousset, A. 2019 Protists: Puppet Masters of the Rhizosphere Microbiome. Trends in Plant Science 24, 165-176. (doi:10.1016/j.tplants.2018.10.011). [28] Rocca, J.D., Yammine, A., Simonin, M. \& Gibert, J.P. 2021 Predation by protists influences the temperature response of microbial communities. (doi:10.1101/2021.04.08.439073).

[29] Cooper, H.F., Grady, K.C., Cowan, J.A., Best, R.J., Allan, G.J. \& Whitham, T.G. 2019 Genotypic variation in phenological plasticity: Reciprocal common gardens reveal adaptive responses to warmer springs but not to fall frost. Global Change Biology 25, 187-200. (doi:10.1111/gcb.14494).

[30] Franks, S.J., Sim, S. \& Weis, A.E. 2007 Rapid evolution of flowering time by an annual plant in response to a climate fluctuation. Proceedings of the National Academy of Sciences 104, 1278-1282. (doi:10.1073/pnas.0608379104).

[31] Franks, S.J. \& Hoffmann, A.A. 2012 Genetics of climate change adaptation. Annual Reviews in Genetics 46, 185-208. (doi:10.1146/annurev-genet-110711-155511). [32] Geerts, A.N., Vanoverbeke, J., Vanschoenwinkel, B., Van Doorslaer, W., Feuchtmayr, H., Atkinson, D., Moss, B., Davidson, T.A., Sayer, C.D. \& De Meester, L. 2015 Rapid evolution of thermal tolerance in the water flea Daphnia. Nature Climate Change 5, 665-668. (doi:10.1038/nclimate2628).

[33] Fox, R.J., Donelson, J.M., Schunter, C., Ravasi, T. \& Gaitan-Espitia, J.D. 2019 Beyond buying time: the role of plasticity in phenotypic adaptation to rapid environmental change. Philosophical Transactions of the Royal Society B: Biological Sciences 374, 20180174. (doi:10.1098/rstb.2018.0174). 